\title{
An inland waterway traffic noise prediction model for environmental assessment in China
}

\author{
B. L. Dai ${ }^{1,2} \cdot$ N. Sheng ${ }^{3} \cdot$ Y. L. He ${ }^{4}$ J. M. Xu ${ }^{1,2} \cdot$ A. F. Zhu ${ }^{1,2}$
}

Received: 21 January 2016/Revised: 5 March 2016/Accepted: 15 March 2016/Published online: 4 April 2016

(C) Islamic Azad University (IAU) 2016

\begin{abstract}
This paper aimed at proposing an inland waterway traffic noise prediction model for environmental assessment in China. The study was the first to predict inland waterway traffic noise levels considering water surface condition and absorption influence in China. The analysis results indicated that the inland waterway traffic noise exposure levels can be influenced by water surface. The model was developed based on the Germany Schall 03 model by adding the water surface condition and absorption correction terms to the governing equations. Results showed that the predicted noise levels by the developed model correlated well with the measurements. In addition, the developed model had higher precision compared with the existing models such as the Schall 03 model, the modified US Federal Highway Administration (FHWA) model and the modified Germany Richtlinien für den Lärmschutz an Straßen (RLS 90) model. The proposed model can be utilized to assess inland waterway traffic noise exposure in China.
\end{abstract}

N. Sheng

nis@must.edu.mo

1 Jiangsu Key Laboratory for Biomass-based Energy and Enzyme Technology, School of Chemistry and Chemical Engineering, Huaiyin Normal University, Huaian 223300, People's Republic of China

2 Jiangsu Collaborative Innovation Center of Regional Modern Agriculture \& Environmental Protection, Huaiyin Normal University, Huaian 223300, People's Republic of China

3 Department of Decision Sciences, Macau University of Science and Technology, Avenida Wai Long, Taipa, Macau, People's Republic of China

4 Faculty of Geosciences and Environmental Engineering, Southwest Jiaotong University, Chengdu 610031, People's Republic of China
Keywords Inland waterway $\cdot$ Schall 03 model $\cdot$ Vessel traffic noise $\cdot$ Water surface influence

\section{Introduction}

Although inland waterway traffic is not dominant source of noise in the environment, it substantially acts as an upsetting and disturbing factor of human activities as well as highway and railway, especially at night when it disturbs sleep of the population living around inland waterways (Prascevic et al. 2013; Kumar et al. 2014). However, unlike those produced by trains and cars, the inland waterway vessel emission noise has not been paid enough attention (Dai et al. 2015). With the increasing number of transport vessels, inland waterway noise pollution will be further intensified in future. Therefore, it is necessary to include measures aiming to reduce noise levels during planning and designing of new inland waterways and reconstruction of the existing ones (Liu et al. 2012).

Traffic noise prediction models are required as aids in the planning and design of urban inland waterways, and also in the assessment of existing or envisaged changes in traffic noise conditions (Pamanikabud and Tansatcha 2003; Monazzam et al. 2015). However, in addition to the modified Federal Highway Administration (FHWA) and Richtlinien für den Lärmschutz an Straßen (RLS 90) models by Dai et al. (2014, 2015), there is still lack of suitable methods for predicting the inland waterway traffic noise. The railway traffic noise prediction models are usually utilized to assess inland waterway traffic noise exposure level. In view of this, to develop a traffic noise model based on the railway traffic noise prediction model relating to the current inland waterway traffic conditions in 
China is regarded as an interesting study (Rajakumara and Gowda 2009).

At present, many popular railway traffic noise prediction models have been designed by different countries (Sheng and Tang 2015). Typical ones include the United States Federal Railway Administration traffic noise model (US DT 2005), the model by the Institute of Railway Comprehensive Technology of Japan (Koyasu 1978), the Önorm S5011 and ÖAL28 models in Austria (ÖN 1995; ÖAL 1987), the Guide du Bruit (GdB) model in France (GBTT 1980), the Beregning af stфj fra jernbaner model in Denmark (Beregning af støj fra jernbaner 1985), the Schall 03 model in Germany (Richtlinie zur berechnung der schallimmissionen von schienenwegen 1990), the Nordic Prediction Method for Train Noise (NMT) model in Norway and Sweden (Kilde Akustikk a/s and the Nordic Council of Ministers 1995; Murphy and King 2010; Chang et al. 2012), the Semibel version 1.0 model in Switzerland (Bundesamtes für umwelt and walt und landschaft und Bundesamtes für Verkehr 1990), the Calculation of Railway Noise (CRN) model in UK (Hardy et al. 2006) and the GIS-based traffic noise model system in Macau City of China (Tang and Wang 2007; Sheng and Tang 2011). Among these methods, the Schall 03 model developed in the Germany has been widely used to calculate railway traffic noise exposure level in China (Gu 2006; Jiang et al. 2012; Zhou et al. 2013; Cui et al. 2014). Therefore, the Schall 03 model is selected to assess inland waterway traffic noise exposure level in this study. However, conditions on railway are apparently different from those on inland waterway. Differences in the emission noise level and type of vehicles, noise measuring methods and traffic conditions all lead to inaccuracies when applying the model to assess inland waterways traffic noise ( $\mathrm{Li}$ et al. 2002). In order to address the aforementioned problems, the parameters in the model are redescribed to meet the inland waterway actual traffic conditions better, and the water surface adjustments are also introduced to determine the noise level influenced by inland waterway water surface condition and absorption in this research. Thus, by adding the water surface condition and absorption correction terms, an improved model to predict inland waterway traffic noise can be established based on the Schall 03 for the calculation of attenuation during noise propagation.

In the next section, the mathematical model based on the Schall 03 that considers water surface condition and absorption influences is presented. In "Results and discussion" section, the developed model is verified by comparing the predicted noise levels by the developed model with those by the Schall 03 model or the modified FHWA and RLS 90 models. Some concluding remarks of this research are given in "Conclusion" section. In this study, data collection was carried out at 10 sampling sites of Yanhe Channel, Huaian City, Jiangsu Province, China, from 9:00 a.m., to 5:00 p.m., on September 12-13, 2015.

\section{Materials and methods}

\section{Mathematical model}

Normal class inland waterways are regarded as long straight segments. Therefore, dividing channel into $k$ segments, and considering the effect of water surface attenuation, the model for each segment to predict the inland waterway traffic noise based on the Schall 03 can be mathematically described as (Richtlinie zur berechnung der schallimmissionen von schienenwegen 1990; Kurze and Weißenberger 2003; Möhler et al. 2006; Prascevic et al. 2013; Dai et al. 2014, 2015)

$$
\begin{aligned}
L_{r, k}= & L_{m, E, k}+19.2+10 \lg l_{k}+D_{l, k}+D_{S, k}+D_{L, k} \\
& +D_{B M, k}+D_{\text {rarr }, k}+10 \lg \left(\frac{d_{0}}{D_{0}}\right)^{1+\beta}+10 \lg \left[\frac{\psi_{a}\left(\varphi_{1,} \varphi_{2}\right)}{\pi}\right]+S
\end{aligned}
$$

where $L_{r, k}$ is the hourly equivalent continuous sound pressure level of $k$ th segment of channel at receiver point (dBA). $L_{m, E, k}$ is the energy mean emission level at a distance of $25 \mathrm{~m}$ from the inland waterway center line (dBA); $l_{k}$ is the length of $k$ th segment of channel $(\mathrm{m})$ and should meet the following relational expression: $0.01 \cdot S_{k} \leq l_{k}$ $\leq 0.5 \cdot S_{k}, S_{k}$ is perpendicular distance from the center point of $k$ th segment of channel to the receiver point $(\mathrm{m}) ; D_{l, k}$ is the correction for directional characteristics of noise (dBA); $D_{S, k}$ is the attenuation due to propagation distance (dBA); $D_{L, k}$ is the attenuation due to air absorption (dBA); $D_{B M, k}$ is the attenuation due to ground and atmospheric effects (dBA); $D_{r a r r, k}$ is the excess attenuation due to barriers, buildings, wood, etc. (dBA); $d_{0}$ is a reference distance at which the energy mean emission level $L_{m, E, k}$ is calculated (m), usually $25 \mathrm{~m}$ according to the German standard Schall 03 and Chinese standard GB/T 4964-2010 (Measurement of noise emitted by vessels on inland waterways and harbors); $D_{0}$ is a reference distance from a emitting vessel to the bank side $(\mathrm{m}) ; \beta$ is a distance attenuation parameter due to water surface absorption. $\psi_{a}$ is a function used for segment inland waterway adjustment. $\varphi_{1}$ and $\varphi_{2}$ are angles at receiver point in degree for inland waterway section under the analysis $\left(^{\circ}\right) ; \varphi_{1}$ is the angle at receiver point measured from perpendicular line of inland waterway centerline to the left most end of the inland waterway segment $\left(^{\circ}\right) ; \varphi_{2}$ is the angle at receiver point measured from perpendicular line of inland waterway centerline to the right most end of the inland waterway segment $\left(^{\circ}\right) . S$ is the attenuation due to the lower noise 
annoyance of inland waterway compared with roadway and railway (dBA), usually $-5 \mathrm{dBA}$.

The total A-weighted hourly equivalent continuous sound pressure level produced by all segments of channel can be mathematically expressed as

$L_{r, g e r}=10 \lg \sum_{i=1}^{k} 10^{\frac{L_{r, k}}{10}}$

where $L_{r, k}$ is the hourly equivalent continuous sound pressure level of $k$ th segment of channel at receiver point $(\mathrm{dBA})$.

\section{Mean emission level $\boldsymbol{L}_{m, E, k}$}

In the analysis of inland waterway traffic noise using the established model based on the Schall 03, vessels can be classified into two acoustic source types, specifically passenger and freight vessel. Based on this, the energy mean emission level $L_{m, E, k}$ can be mathematically written as

$$
\begin{aligned}
L_{m, E, k}= & 10 \lg \left[\sum_{i=1}^{N} 10^{0.1\left(L_{A}+D_{F c}+D_{D}+D_{L}+D_{v}\right)}\right]+D_{F b}+D_{B r} \\
& +D_{B u}+D_{R u}
\end{aligned}
$$

where the same type and speed of vessels are classified as a class, denoted as $i ; N$ is the number of the $i$ th class of vessels passing in $1 \mathrm{~h} ; L_{A}$ is the reference energy emission level of the $i$ th class vessel at the reference distance $d_{0}(\mathrm{dBA}) ; D_{F c}$ is the correction for vessel types (dBA); $D_{D}$ is the correction for vessel brake types (dBA); $D_{L}$ is the correction for vessel length (dBA); $D_{v}$ is the correction for vessel speed (dBA); $D_{F b}$ is the correction for water surface conditions (dBA); $D_{B r}$ is the attenuation due to bridge effects $(\mathrm{dBA}) ; D_{B u}$ is the attenuation due to tunnel effects (dBA); and $D_{R u}$ is the correction for curve radius of inland waterways (dBA).

Considering the actual inland waterway environmental condition in China, the reference energy emission level $L_{A}$ is given as

Passenger vessel : $L_{A}=78+30 \lg \left(\frac{v}{v_{0}}\right)$;

Freight vessel : $L_{A}=80+30 \lg \left(\frac{v}{v_{0}}\right)$

where $v$ is the measured vessel speed $(\mathrm{km} / \mathrm{h}) ; v_{0}$ is the reference vessel speed $(\mathrm{km} / \mathrm{h})$, and its reference values of passenger and freight vessel are 60 and $50 \mathrm{~km} / \mathrm{h}$, respectively.

According to the German standard Schall 03, the correction $D_{F c}$ for vessel types can be given as in Table 1. It ranges from -4 to $0 \mathrm{dBA}$.

Here, the vessel can be regarded as other type vehicle. Therefore, the values of $D_{F c}$ correction for vessel types can be selected to be $0 \mathrm{dBA}$.

Table 1 The values of $D_{F c}$ correction for vessel types (dBA)

\begin{tabular}{lr}
\hline Vehicle type & $D_{F c}$ \\
\hline 1 Vehicle with wheel damping device & -4 \\
2 Vehicle with disk brake & -1 \\
3 Subway & 2 \\
4 Urban rail train & 3 \\
5 Other & 0 \\
\hline
\end{tabular}

Table 2 The $D_{F b}$ correction values under different speed limits (dBA)

\begin{tabular}{llll}
\hline Surface type & $30 \mathrm{~km} / \mathrm{h}$ & $40 \mathrm{~km} / \mathrm{h}$ & $\geq 50 \mathrm{~km} / \mathrm{h}$ \\
\hline 1 Smooth or concrete asphalt & 0 & 0 & 0 \\
2 Concrete & 1.0 & 1.5 & 2.0 \\
3 Smooth surface & 3.0 & 2.5 & 3.0 \\
4 Other & 3.0 & 4.5 & 6.0 \\
\hline
\end{tabular}

The correction $D_{D}$ for vessel brake types is calculated according to the following equation

$D_{D}=10 \lg (5-0.04 \cdot p)$

where $p$ is the percentage of vehicle with disk brake (\%).

The correction $D_{L}$ for vessel length can be obtained using

$D_{L}=10 \lg (0.01 \cdot l)$

where $l$ is the total length of the $i$ th class vessels passing in $1 \mathrm{~h}(\mathrm{~m})$.

The correction $D_{v}$ for vessel speed is given as

$D_{v}=20 \lg (0.01 \cdot v)$

where $v$ is the $i$ th class passing vessels speed $(\mathrm{km} / \mathrm{h})$.

The correction $D_{F b}$ for surface condition can be given as in Table 2 and depends upon the kind of surface and the vessel speed. It ranges from 0 to $6.0 \mathrm{dBA}$.

According to the actual inland waterway water surface condition, it can be regarded as a smooth surface. Therefore, the $D_{F b}$ correction values for water surface condition can be selected to be 2.5 or $3.0 \mathrm{dBA}$.

For normal class inland waterways, they are regarded as not passing the bridge and tunnel; therefore, the corrections $D_{B r}$ and $D_{B u}$ for inland waterway segment can be neglected.

The correction $D_{R u}$ for curve radius of inland waterways is given as in Table 3 .

Table 3 The values of $D_{R u}$ correction for curve radius of inland waterways (dBA)

\begin{tabular}{ll}
\hline Curve radius $(R)$ & $D_{R u}$ \\
\hline$R<300 \mathrm{~m}$ & 8 \\
$300 \mathrm{~m}<R<500 \mathrm{~m}$ & 3 \\
$R>500 \mathrm{~m}$ & 0 \\
\hline
\end{tabular}


The correction $D_{l, k}$ for directional characteristics of noise

The correction $D_{l, k}$ for directional characteristics of noise is given as

$D_{l, k}=10 \lg \left(0.22+1.27 \sin ^{2} \theta_{k}\right)$

where $\theta_{k}$ is the angle at receiver point measured from connective line between the emitting and receiver points to inland waterway segment centerline $\left(^{\circ}\right)$.

\section{The propagation distance attenuation correction \\ $D_{S, k}$}

The attenuation term $D_{S, k}$ due to propagation distance is given as

$D_{S, k}=10 \lg \left(\frac{1}{2 \pi \cdot S_{k}^{2}}\right)$

where $S_{k}$ is perpendicular distance from the center point of $k$ th segment of channel to the receiver point $(\mathrm{m})$.

\section{The air absorption attenuation correction $D_{L, k}$}

Following the German standard Schall 03, the attenuation correction due to air absorption $\left(D_{L, k}\right)$ can be redescribed as

$D_{L, k}=-\frac{S_{k}}{200}$

where $S_{k}$ is perpendicular distance from the center point of $k$ th segment of channel to the receiver point (m).

\section{The correction $D_{B M, k}$ for the attenuation due to ground and atmospheric effects}

The attenuation correction $D_{B M, k}$ due to ground and atmospheric effects is calculated according to the following equation

$D_{B M, k}=\frac{h_{m}}{S_{k}}\left(34+\frac{600}{S_{k}}\right)-4.8$

where $h_{m}$ is the average height of connective line between the emitting and receiver point from the ground surface; $S_{k}$ is perpendicular distance from the center point of the $k$ th segment of channel to the receiver point $(\mathrm{m})$.

\section{The barrier shielding attenuation correction $D_{\text {rarr,k }}$}

The correction term $D_{\text {rarr }, k}$ for the attenuation due to barrier shielding is given as

$$
\begin{aligned}
D_{r a r r, k} & =10 \lg \left(3+80 \cdot \delta_{k} \cdot K_{w, k}\right) \\
\delta_{k} & =a+b-s_{\perp} \\
K_{w, k} & =\exp \left(-\frac{1}{2000} \cdot \sqrt{\frac{a \cdot b \cdot s_{\perp}}{2 \delta_{k}}}\right)
\end{aligned}
$$

where $\delta_{k}$ is the sound path difference $(\mathrm{m}) ; a$ is the distance from the noise source to the obstacle top $(\mathrm{m}) ; b$ is the distance from the obstacle top to the receiver (m); $s_{\perp}$ is the connective line length from the emitting vessel to the receiver (m); and $K_{w, k}$ is attenuation due to air temperature and wind speed $(\mathrm{dBA})$.

\section{The distance attenuation parameter due to water surface absorption}

The distance attenuation parameter $\beta$ due to water surface absorption can be mathematically expressed as (Dai et al. 2014, 2015)

$\beta=\frac{L_{0 i}-L_{1 i}}{20 \lg \frac{D_{0}}{d}}-1$

where $L_{0 i}$ is the reference energy mean emission level of the $i$ th class of vessels measured at the reference distance $d_{0}=25 \mathrm{~m}(\mathrm{dBA})$, and $L_{1 i}$ is the energy mean emission level of the $i$ th class of vessels at other measuring distances $d(\mathrm{dBA})$.

The measured data were collected at 7 sampling sites at the water surface around Jianbi vessel lock in Zhenjiang City of China. The analogy data are adopted to calibrate $\beta$. The other perpendicular distances for measuring the energy mean emission level $L_{1 i}$ are selected at 1, 10, 20 and $30 \mathrm{~m}$ for light vessels, and 1, 10,15 and $29 \mathrm{~m}$ for heavy vessels from the side of the measured vessels to the receiver, respectively. After statistical averaging operation, the distance attenuation parameter due to water surface $\beta$ is calibrated to the value -0.121 .

\section{The finite length channel adjustment}

For normal class inland waterways, they are regard as infinite in most cases; therefore, the adjustment $10 \lg \left[\frac{\psi_{a}\left(\varphi_{1}, \varphi_{2}\right)}{\pi}\right]$ for finite length of inland waterway segment can be neglected (Dai et al. 2015).

The calculation procedures designed for predicting inland waterway traffic noise based on the Schall 03 model are shown in Fig. 1. 


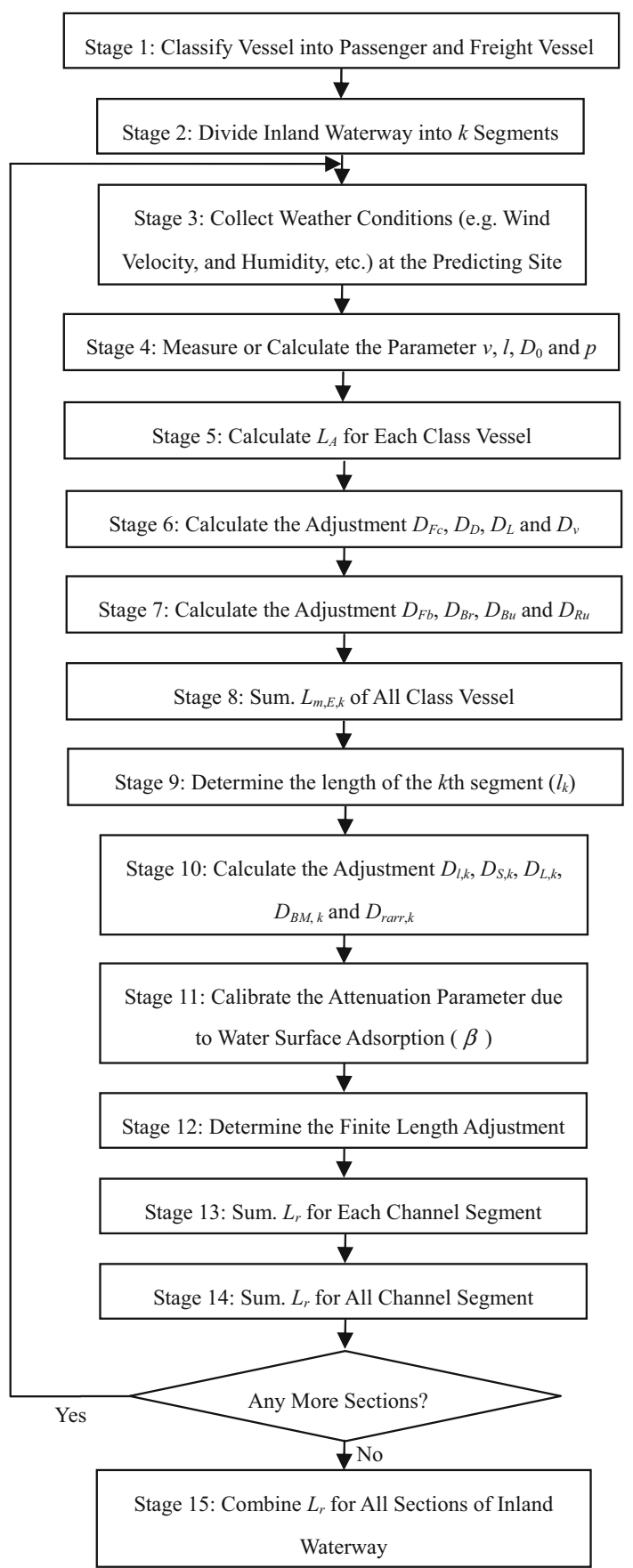

Fig. 1 Designed procedure for predicting traffic noise levels based on the Schall 03 model

\section{Field measurements}

The data were collected at 10 sampling sites of Yanhe Channel in Huaian City in China from 9:00 a.m., to 5:00 p.m., on weekdays of September in 2015, as shown in Table 4. Due to the description of the Schall 03 model and Chinese standard GB/T 4964-2010, these sampling sites for monitoring inland waterway traffic noise levels were set up
$1.0 \mathrm{~km}$ from each other and were located at least $5.0 \mathrm{~m}$ from buildings at a height of $1.5 \mathrm{~m}$. There were no screens, barriers and buildings between the noise source and the sampling sites. Under moderate weather with a wind speed less than $1.5 \mathrm{~m} / \mathrm{s}$, in surveying the 60 -min time-weightedaverage $L_{r, g e r}$ for all two types of vessels, the microphones (AIHUA AWA5661) was set at $1.2 \mathrm{~m}$ above the local ground level according to the Chinese standard GB 3096-2008 (Environmental quality standard for noise), and it was corrected by noise calibrator (AIHUA AWA6224S) before each use. Simultaneously, as shown in Fig. 2, other traffic parameters were also underway. These parameters include river embankment's height from the water surface $\left(h_{0}\right)$ measured on the other side of the river embankment away from the water surface, the height of the source $\left(h_{1}\right)$, the height of the receiver from the water surface $\left(h_{2}\right)$, the distance from the noise source to the obstacle top $(a)$, the distance from the obstacle top to the receiver $(b)$, the connective line length from the emitting vessel to the receiver $\left(s_{\perp}\right)$, the distance between the river embankment and the receiver $\left(d_{1}\right)$, and the reference distance from the emitting vessel to the river embankment side $\left(D_{0}\right)$. In addition, a laser speed gun (VICTOR DM6236P) was used to measure vessel speeds, a video-recorder (Canon LEGRIA HF R56) was used to determine traffic flow and vessel types, and a laser distance measuring instrument (MILESEEY S9) was used to measure river embankment's height from the water surface $\left(h_{0}\right)$, the height of the source $\left(h_{1}\right)$ and so on. The traffic and environmental data were measured during a 60-min time period. The background noise levels were measured when there is no vessel pass through the receiver point.

\section{Results and discussion}

\section{Model verification}

In order to test the accuracy of the inland waterway traffic noise prediction model developed in this study, we compared the measured noise levels with the predicted noise levels using a propagation distance correction, an air absorption correction, a water surface condition correction, a water surface absorption correction, a vessel length correction, a vessel speed correction and a ground absorption correction, which are based on the measured and modeled $L_{r, \text { ger }}$ obtained at 10 sampling sites. The developed prediction model in this study was validated using the data collected at the above-mentioned 10 sampling sites. The calculation area partition used in the modified traffic noise model on inland waterway is shown in Fig. 3. Detailed differences between the predicted and measured noise levels at each sampling site are presented in Table 5. 
Table 4 The measured or calculated parameters of the samples

\begin{tabular}{|c|c|c|c|c|c|c|c|c|c|c|}
\hline \multirow[t]{2}{*}{ Samples } & \multirow[t]{2}{*}{$\begin{array}{l}\text { Sampling } \\
\text { sites }\end{array}$} & \multirow[t]{2}{*}{$\begin{array}{l}\text { Vessel } \\
\text { types }\end{array}$} & \multirow[t]{2}{*}{$\begin{array}{l}\text { Total vessel } \\
\text { length }(\mathrm{m})\end{array}$} & \multirow[t]{2}{*}{$\begin{array}{l}\text { Total traffic } \\
\text { flow }(/ \mathrm{h})\end{array}$} & \multirow[t]{2}{*}{$\begin{array}{l}\text { Vessel speed } \\
(\mathrm{km} / \mathrm{h})\end{array}$} & \multirow[t]{2}{*}{$\begin{array}{l}S_{k} \\
(\mathrm{~m})\end{array}$} & \multicolumn{2}{|c|}{$\begin{array}{l}\text { Vessel traveling direction at } \\
\text { the monitoring points }\end{array}$} & \multirow[t]{2}{*}{$L_{m, E}$} & \multirow[t]{2}{*}{$\begin{array}{l}h_{0} \\
(\mathrm{~m})\end{array}$} \\
\hline & & & & & & & $\begin{array}{l}\text { Along } \\
\text { current }(\%)\end{array}$ & $\begin{array}{l}\text { Against } \\
\text { current }(\%)\end{array}$ & & \\
\hline \multirow[t]{2}{*}{1} & \multirow[t]{2}{*}{$\mathrm{Z} 1$} & \multirow{2}{*}{$\begin{array}{l}\text { Freight } \\
\text { vessel }\end{array}$} & 585 & 9 & 20 & \multirow[t]{2}{*}{200} & \multirow[t]{2}{*}{55} & \multirow[t]{2}{*}{45} & \multirow[t]{2}{*}{77.9} & \multirow[t]{2}{*}{0.12} \\
\hline & & & 170 & 2 & 32 & & & & & \\
\hline \multirow[t]{3}{*}{2} & \multirow[t]{3}{*}{$\mathrm{Z} 2$} & \multirow{3}{*}{$\begin{array}{l}\text { Freight } \\
\text { vessel }\end{array}$} & 325 & 5 & 20 & \multirow[t]{3}{*}{183} & \multirow[t]{3}{*}{78} & \multirow[t]{3}{*}{22} & \multirow[t]{3}{*}{82.1} & \multirow[t]{3}{*}{0.09} \\
\hline & & & 255 & 3 & 32 & & & & & \\
\hline & & & 105 & 1 & 40 & & & & & \\
\hline \multirow[t]{3}{*}{3} & $\mathrm{Z3}$ & Freight & 390 & 6 & 15 & 165 & 56 & 44 & 82.5 & 0.35 \\
\hline & & vessel & 210 & 2 & 35 & & & & & \\
\hline & & & 105 & 1 & 40 & & & & & \\
\hline 4 & $\mathrm{Z} 4$ & Freight & 520 & 8 & 20 & 192 & 91 & 9 & 75.8 & 0.47 \\
\hline & & vessel & 255 & 3 & 26 & & & & & \\
\hline 5 & $\mathrm{Z} 5$ & Freight & 195 & 3 & 15 & 155 & 69 & 31 & 81.6 & 0.51 \\
\hline & & vessel & 455 & 7 & 20 & & & & & \\
\hline & & & 170 & 2 & 32 & & & & & \\
\hline & & & 105 & 1 & 40 & & & & & \\
\hline 6 & Z6 & Freight & 650 & 9 & 15 & 170 & 64 & 36 & 74.0 & 0.28 \\
\hline & & vessel & 195 & 3 & 20 & & & & & \\
\hline & & & 170 & 2 & 26 & & & & & \\
\hline 7 & $\mathrm{Z7}$ & Freight & 520 & 8 & 15 & 143 & 62 & 38 & 70.7 & 0.33 \\
\hline & & vessel & 325 & 5 & 20 & & & & & \\
\hline 8 & Z8 & Freight & 780 & 12 & 15 & 150 & 75 & 25 & 76.0 & 0.40 \\
\hline & & vessel & 390 & 6 & 20 & & & & & \\
\hline & & & 255 & 2 & 26 & & & & & \\
\hline 9 & Z9 & Freight & 520 & 8 & 15 & 165 & 61 & 39 & 82.8 & 0.55 \\
\hline & & vessel & 390 & 6 & 20 & & & & & \\
\hline & & & 170 & 2 & 32 & & & & & \\
\hline & & & 105 & 1 & 35 & & & & & \\
\hline & & & 105 & 1 & 40 & & & & & \\
\hline 10 & $\mathrm{Z} 10$ & Freight & 715 & 11 & 20 & 195 & 80 & 20 & 80.1 & 0.22 \\
\hline & & vessel & 170 & 2 & 26 & & & & & \\
\hline & & & 85 & 1 & 32 & & & & & \\
\hline & & & 105 & 1 & 35 & & & & & \\
\hline
\end{tabular}

Fig. 2 Parameters used in the modified traffic noise model on inland waterway

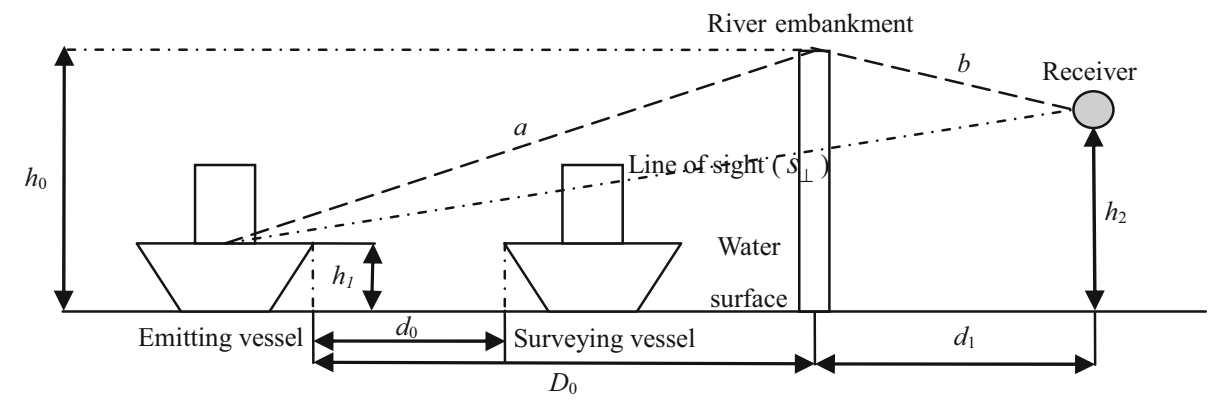




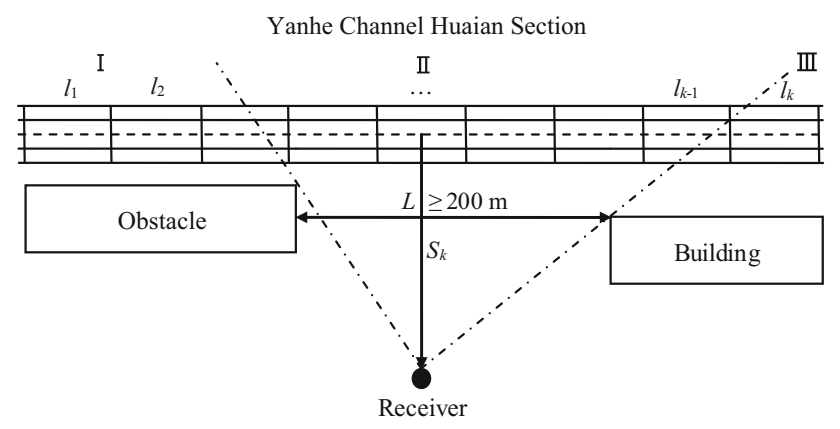

Fig. 3 Schematic diagram showing calculation area partition used in the modified traffic noise model on inland waterway

Similarly, Fig. 4 indicates comparison between measured and predicted noise levels at 10 sampling sites in the developed prediction model, the shall 03 model, the modified FHWA model and RLS 90 model.

It can be seen from Table 5 and Fig. 4 a that the deviation between the predicted and measured noise levels is within a range of $\pm 1.5 \mathrm{dBA}$ for $90 \%$ of the sampling sites. The average value of differences between the predicted and measured noise levels for 10 sampling sites is $1.0 \mathrm{dBA}$ and the standard error $\left(\sigma_{s}\right)$ is $1.2 \mathrm{dBA}$. In contrast, the deviation between the predicted and measured noise levels is only within a range of $\pm 1.5 \mathrm{dBA}$ for $20 \%$ of sampling sites, and the average value of differences between the predicted and measured noise levels for 10 sampling sites is $1.8 \mathrm{dBA}$ and the standard error $\left(\sigma_{s}\right)$ is $2.3 \mathrm{dBA}$ in the Schall 03 model (see Fig. 4b). These results were improved to be 0.3 and $0.7 \mathrm{dBA}$ (average difference) while using the modified FHWA and RLS 90 models, respectively, as shown in Fig. $4 \mathrm{c}$, d. In general, the developed method predicted noise levels that were higher than the measured levels for major receivers. Moreover, the results indicated that the predicted values by the developed model in the study were of higher accuracy than those by the Schall 03 model and the modified FHWA and RLS 90 models, and it was also shown that the developed model has better application in practice use.

\section{Model comparison}

A modified prediction model based on the Schall 03 is used here to evaluate traffic noise exposure levels of inland waterway. On average, the predicted hourly equivalent continuous noise level $\left(L_{r, g e r}\right)$ is $60.1 \mathrm{dBA}$ for all sampling sites and 59.0 dBA for measured noise levels. Although the noise prediction model tended to overestimate the actual noise exposure levels, the predicted hourly equivalent continuous noise levels are highly correlated with measured noise levels $\left(R^{2}=0.97418\right.$; Fig. $\left.4 \mathrm{a}\right)$, suggesting that the developed model based on the Schall 03 can approximately reflect actual noise exposure levels in the study region.

The present study is the first to predict inland waterway traffic noise levels considering water surface condition and absorption influence in China. Our analysis results indicate that the inland waterway traffic noise exposure levels can be influenced by water surface (see Table 5; Fig. 4). Accordingly, this modified method has a greater precision (i.e., $\sigma_{s}=1.2$ vs. $2.3 \mathrm{dBA}$ ) than that of the Schall 03 model. One main reason for the improved prediction model is the inclusion of water surface condition and absorption influence correction terms in the predictive equations.

Compared with the modified FHWA and RLS 90 models, the method still has better precision and accuracy ( $\sigma_{s}=1.2$ vs. 2 vs. $1.9 \mathrm{dBA}$ ). Possible reasons may be due

Table 5 Differences between the measured and predicted noise levels of $L_{r, g e r}$ at 10 sampling sites of Yanhe Channel in Huaian City, China $(\mathrm{dBA})$

\begin{tabular}{|c|c|c|c|c|c|c|c|c|c|c|}
\hline $\begin{array}{l}\text { Sampling } \\
\text { sites }\end{array}$ & $\begin{array}{l}\text { Background } \\
\text { noise levels }\end{array}$ & $\begin{array}{l}\text { Measured } \\
\text { levels (A) }\end{array}$ & $\begin{array}{l}\text { Predicted by } \\
\text { the developed } \\
\text { model (B) }\end{array}$ & $\begin{array}{l}\text { Predicted by } \\
\text { the Schall } 03 \\
\text { model }(\mathrm{C})\end{array}$ & $\begin{array}{l}\text { Predicted by the } \\
\text { modified FHWA } \\
\text { model }^{\mathrm{a}}(\mathrm{D})\end{array}$ & $\begin{array}{l}\text { Predicted by the } \\
\text { modified RLS } 90 \\
\text { model }^{\mathrm{a}}(\mathrm{E})\end{array}$ & B-A & $\mathrm{C}-\mathrm{A}$ & D-A & $\mathrm{E}-\mathrm{A}$ \\
\hline $\mathrm{Z1}$ & 45.3 & 58.5 & 59.8 & 60.7 & 60.0 & 60.2 & 1.3 & 2.2 & 1.5 & 1.7 \\
\hline $\mathrm{Z} 2$ & 48.6 & 62.3 & 63.8 & 64.6 & 64.8 & 64.6 & 1.5 & 2.3 & 2.5 & 2.3 \\
\hline $\mathrm{Z3}$ & 46.5 & 61.8 & 62.8 & 64.7 & 64.1 & 63.9 & 1.0 & 2.9 & 2.3 & 2.1 \\
\hline $\mathrm{Z} 4$ & 43.1 & 57.2 & 56.7 & 60.0 & 59.0 & 58.6 & -0.5 & 2.8 & 1.8 & 1.4 \\
\hline $\mathrm{Z} 5$ & 44.2 & 59.9 & 60.5 & 59.0 & 61.0 & 60.8 & 0.6 & -0.9 & 1.1 & 0.9 \\
\hline Z6 & 42.3 & 55.9 & 56.8 & 54.8 & 54.2 & 54.1 & 0.9 & -1.1 & -1.7 & -1.8 \\
\hline $\mathrm{Z7}$ & 41.8 & 52.6 & 53.8 & 55.2 & 54.5 & 51.0 & 1.2 & 2.6 & 1.9 & -1.6 \\
\hline Z8 & 42.9 & 56.7 & 58.1 & 58.6 & 59.3 & 58.5 & 1.4 & 1.9 & 2.6 & 1.8 \\
\hline Z9 & 48.8 & 65.1 & 66.7 & 67.6 & 67.3 & 67.9 & 1.6 & 2.5 & 2.2 & 2.8 \\
\hline $\mathrm{Z} 10$ & 46.7 & 60.4 & 61.5 & 63.1 & 62.5 & 62.1 & 1.1 & 2.7 & 2.1 & 1.7 \\
\hline
\end{tabular}

${ }^{a}$ The detailed calculation procedure of the modified FHWA and RLS 90 model can be seen in Dai et al. (2014; 2015) 
Fig. 4 Comparison between the measured and predicted noise levels $\left(L_{r, g e r}, \mathrm{dBA}\right)$ at 10 sampling sites by a the developed prediction model, b the Schall 03 model, $\mathbf{c}$ the modified FHWA model and d the modified RLS 90 model
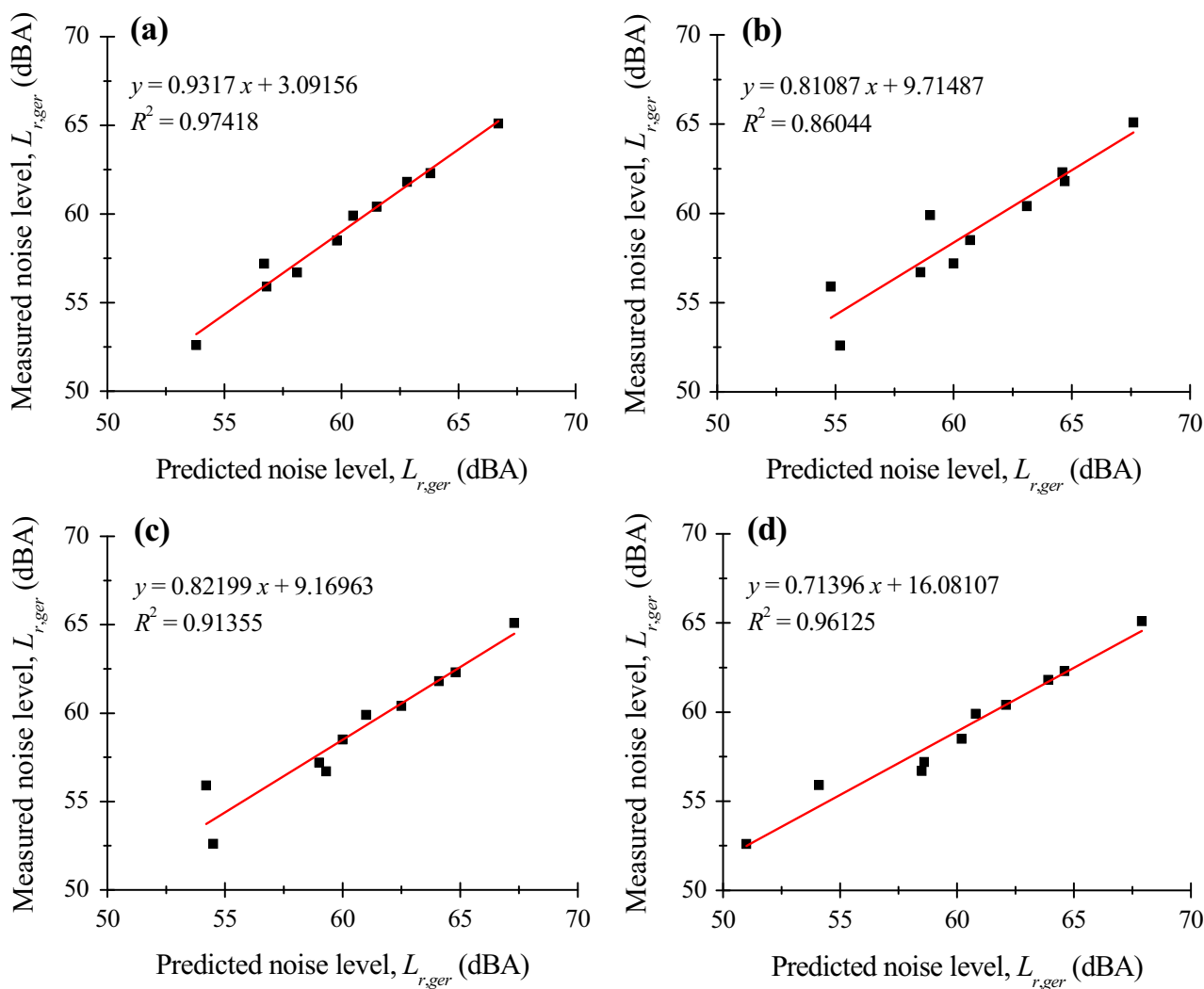

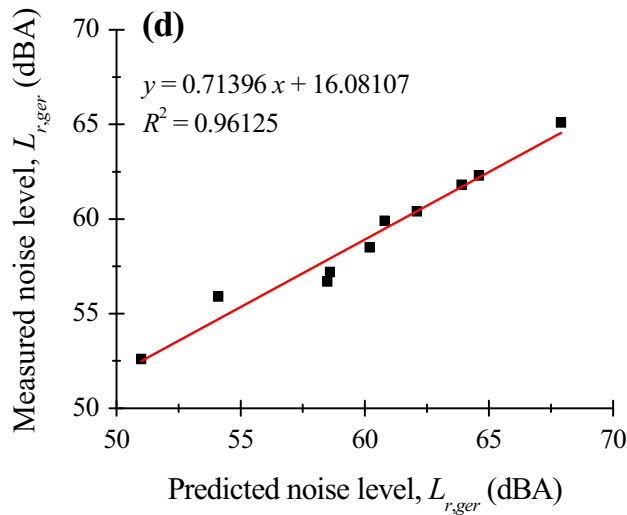

to neglecting effects of water surface condition in the field when utilize the modified FHWA model to assess noise levels (see Table 6), and for the modified RLS 90 model, the traffic vessel length and inland waterway curve radius influence are not considered. In general, the relative comparison results show that the simulation accuracy varies from high to low: the developed model $>$ the modified
RLS 90 model $>$ the modified FHWA model $>$ the Schall 03 model.

Based on the aforementioned analysis, although the improved method is effective and reliable, there are some limitations for using this improved model to predict inland waterway traffic noise levels. These limitations come from the inherent assumptions of the Schall 03 prediction

Table 6 Comparison of the developed prediction model, the Schall 03 model and the modified FHWA and RLS 90 models

\begin{tabular}{|c|c|c|c|c|}
\hline The adjustment factors & $\begin{array}{l}\text { The developed } \\
\text { prediction model }\end{array}$ & $\begin{array}{l}\text { The Schall } \\
03 \text { model }\end{array}$ & $\begin{array}{l}\text { The modified } \\
\text { FHWA model }\end{array}$ & $\begin{array}{l}\text { The modified } \\
\text { RLS } 90 \text { model }\end{array}$ \\
\hline Traffic vessel type, flow and speed & Yes & Yes & Yes & Yes \\
\hline Traffic vessel length & Yes & Yes & No & No \\
\hline Traffic vessel brake type & Yes & Yes & No & No \\
\hline Water surface condition & Yes & No & No & Yes \\
\hline The attenuation due to distance & Yes & Yes & Yes & Yes \\
\hline The water surface gradient along vessel travel direction & No & No & No & Yes \\
\hline The attenuation due to air absorption & Yes & Yes & No & Yes \\
\hline Ground absorption & Yes & Yes & Yes & Yes \\
\hline Atmospheric effect & Yes & Yes & No & Yes \\
\hline The attenuation due to barriers, buildings, etc. & Yes & Yes & Yes & Yes \\
\hline The distance attenuation due to water surface absorption & Yes & No & Yes & Yes \\
\hline The attenuation due to curve radius of inland waterway & Yes & Yes & No & No \\
\hline Finite length channel adjustment & Yes & Yes & Yes & Yes \\
\hline River bank shielding & No & No & No & No \\
\hline
\end{tabular}

Yes: considering; No: not considering 
method, for instance, the reference speed is used instead of the actual average speed in the model (Möhler et al. 2006; Chang et al. 2012). These limitations may cause $0.339 \mathrm{dBA}$ in the mean square error between the measured and predicted traffic noise levels.

In addition, no water surface gradient along vessel travel direction and river bank shielding corrections are applied in this improved model because of the lack of related information. This uncorrected factor may contribute to overestimated inland waterway traffic noise levels among the surrounding areas (Dai et al. 2014). However, this limitation can be overcome when these data are available for each study case.

Comparison of the obtained results with the modified RLS 90 model, the modified FHWA model and the Schall 03 model has proven that the proposed method was more effective and accurate. Therefore, aiming at the lack of inland waterway noise prediction model in China, to develop a more accurate noise prediction model will be regarded as a meaningful study. Meanwhile, it is expected that the improved prediction method based on the Schall 03 will be widely used to forecast inland waterway traffic noise exposure level.

\section{Conclusion}

Inland waterway traffic noise is one of the major environmental issues affecting human health and well-being in urban environments. The objective of this study was to develop a prediction model for assessing traffic noise impact on the population near the main inland waterways inside the urban perimeter in China. Considering the water surface condition and absorption influences, an inland waterway traffic noise prediction model based on the Germany Schall 03 was proposed in this paper. A comparison of the results of the measured and predicted noise levels with respect to overall value showed good correspondence when adding the water surface condition and absorption correction terms to the calculating equations. In addition, results of present study also revealed that the developed model had higher precision than the Schall 03 model, the modified US FHWA model and the modified Germany RLS 90 model. Therefore, the proposed model can be effectively utilized to assess inland waterway traffic noise exposure level in China.

Acknowledgments This work was financially supported by the Open Foundation of Jiangsu Collaborative Innovation Center of Regional Modern Agriculture \& Environmental Protection of China (HSXT312, HSXT227), and the Natural Science Fund for Colleges and Universities in Jiangsu Province of China (15KJD480001).

\section{References}

Beregning af støj fra jernbaner (1985) Fælles Nordisk beregningsmethode, Vejledning fra Miljøstyrelsen Nr. 5, Copenhagen, Denmark, 1985 (in Danish)

Bundesamtes für umwelt, walt und landschaft und Bundesamtes für Verkehr (1990) Semibel version 1.0, Schweizerisches emissionsund immissionsmodell für die berechnung von eisenbahnlärm, Schriftenreihe Umweltschutz Nr.116, Bundesamtes für umwelt, walt und landschaft und Bundesamtes für Verkehr, Bern, Austria (in German)

Chang TY, Lin HC, Yang WT, Bao BY, Chan CC (2012) A modified Nordic prediction model of road traffic noise in a Taiwanese city with significant motorcycle traffic. Sci Total Environ 432:375-381

Cui RX, Gao L, Cai XP, Hou BW (2014) Vibration and noise reduction properties of different damped rails in high-speed railway. Noise Control Eng J 62:176-185

Dai BL, He YL, Mu FH, Xu N, Wu Z (2014) Development of a traffic noise prediction model on inland waterway of China using the FHWA. Sci Total Environ 482-483:480-485

Dai BL, He YL, Xu JM, Xu N, Wu Z, Deng YF (2015) Applying the RLS 90 to develop an inland waterway traffic noise prediction model in China that considers water surface influence. J Low Freq Noise Vib Act 34(1):73-86

Gu XA (2006) Railway environmental noise control in China. J Sound Vib 293:1078-1085

Guide du Bruit des Transports Terrestres (GBTT) (1980) Prevision des niveaux sonores, Ministere del'environnement et du cadre de vie et Ministere des transports Direction générale des transports intérieurs, Bagneux, France (in French)

Hardy AEJ, Jones RRK, Turner S (2006) The influence of real-world rail head roughness on railway noise prediction. J Sound Vib 293:965-974

Jiang WK, Zhang HB, Yan L (2012) Analysis and reduction techniques for noise of lifted railway transportation. Tech Acoust 31:138-146

Kilde Akustikk a/s and the Nordic Council of Ministers (1995) The Nordic prediction method for train noise (NMT) (Draft), Report R790, Kilde Akustikk a/s and The Nordic council of ministers, the traffic group (NTG), Voss, Denmark

Koyasu M (1978) Method of prediction and control of road traffic noise in Japan. In: Inter-noise 78, San Francisco

Kumar K, Parida M, Katiyar VK (2014) Optimized height of noise barrier for non-urban highway using artificial neural network. Int J Environ Sci Technol 11:719-730

Kurze UJ, Weißenberger W (2003) Der Aufbau einer Datenbank als Grundlage für eine neue Schall 03 (Development of a data base for a new Schall 03), Müller-BBM Report No. 52253/9 for Deutsche Bahn

Li BG, Tao S, Dawson RW, Cao J, Lam K (2002) A GIS based road traffic noise prediction model. Appl Acoust 63:679-691

Liu CR, Xu DL, Ji JF (2012) Theoretical design and experimental verification of a tunable floating vibration isolation system. J Sound Vib 331:4691-4703

Möhler U, Liepert M, Kurze U, Onnich H (2006) The new German prediction model for railway noise Schall 03 2006. In: Some proposals for the harmonised calculation method in the EU directive on environmental noise Euronoise, Tampere, Finland

Monazzam MR, Karimi E, Nassiri P, Taghavi L (2015) Schoolreopening impact on traffic-induced noise level at different land uses: a case study. Int J Environ Sci Technol 12:3089-3094

Murphy E, King EA (2010) Strategic environmental noise mapping: methodological issues concerning the implementation of the EU 
Environmental Noise Directive and their policy implications. Environ Int 36:290-298

Österreichischer Arbeitsring für Lärmbekämpfung (ÖAL) (1987) Schallabstrahlung und Schallausbreitung, ÖAL 28, Österreichischer Arbeitsring für Lärmbekämpfung, Vienna, Austria (in German)

Österreichisches Normungsinstitut (ÖN) (1995) Berechnung der schallimmission durch schienenverkehr, Zugverkehr, verschubund umschlagbetrieb, Önorm S 5011, Österreichisches Normungsinstitut, Vienna, Austria (in German)

Pamanikabud P, Tansatcha M (2003) Geographical information system for traffic noise analysis and forecasting with the appearance of barriers. Environ Model Softw 18:959-973

Prascevic M, Gajicki A, Mihajlov Zivkovic N, Zivkovic L (2013) Application of the prediction model "Schall 03" for railway noise calculation in Serbia. Appl Mech Mater 430:237-243

Rajakumara HN, Gowda RMM (2009) Road traffic noise prediction model under interrupted traffic flow condition. Environ Model Assess 14:251-257
Richtlinie zur berechnung der schallimmissionen von schienenwegen (1990) Schall 03/Akustik 03, Deutsche Bundesbahn, Bundesbahn Zentralamt, München, Germany (in German)

Sheng N, Tang UW (2011) Spatial analysis of urban form and pedestrian exposure to traffic noise. Int $\mathbf{J}$ Environ Res Public Health 8:1977-1990

Sheng N, Tang UW (2015) Spatial techniques to visualize acoustic comfort along cultural and heritage routes for a world heritage city. Sustainability 7:10264-10280

Tang UW, Wang ZS (2007) Influences of urban forms on trafficinduced noise and air pollution: results from a modelling system. Environ Modell Softw 22:1750-1764

US Department of Transportation (US DT) (2005) High-speed ground transportation noise and vibration impact assessment. US Department of Transportation, Washington

Zhou X, Xiao XB, He B, Zhang J, Zhao Y, Han JG, Jin XS (2013) Numerical model for predicting the noise reduction of noise barrier of high speed railway and its test validation. J Mech Eng 49:14-19 